\title{
Considerações acerca de um jovem pais que envelhece
}

\author{
Renato Peixoto Veras*
}

O envelhecimento da população é hoje um fenômeno universal, característica tanto dos paises centrais como, de modo crescente, dos paises do Terceiro $M$ undo. Os fatores responsáveis pelo envelhecimento são discutidos, e o processo conhecido por "transição demográfica" abordado. As repercussōes para a sociedade do progressivo envelhecimento da populaçāo são consideradas, particularmente no que diz respeito à saúde. A mudança do papel da mulher no mundo contemporâneo, o período de vida mais longo e suas conseqüências, entre outros tópicos, fazem parte de uma discussão específica relativa à mulher idosa.

Os problemas da velhice normalmente estão associados aos países desenvolvidos. É neles que a proporção da população acima de sessenta anos já atingiu, há várias décadas, níveis bastante expressivos. No entanto, um fato que está passando despercebido é que, desde o início da década de setenta, mais de metade das pessoas que chegam aos sessenta anos vivem em países do Terceiro Mundo, e as projeções demográficas indicam que de 1980 até o final do século, cerca de três quartos do aumento da população idosa ocorrerão em tais países, fazendo com que este seja o grupo etúrio que mais crescerá na maioria dos países menos desenvolvidos. A longo prazo, as perspectivas são ainda mais impressionantes; a Tabela 1 mostra o aumento das populações idosas em países que terão dezesseis milhões ou mais de pessoas acima de sessenta anos no ano 2025 comparado com as populações da mesma faixa etária em outros períodos. Entre os onze países com as maiores populaçōes de idosos daqui a quarenta anos, oito situam-se na categoria de países em desenvolvimento de acordo com os critérios atuais. Haverá portanto uma substituição; as grandes populaçōes idosas dos países europeus cederāo lugar a países caracteristicamente jovens como a Nigéria, o Brasil ou o Paquistão. O aumento é sem precedentes; por exemplo, o Brasil ocupava no ano de 1950 o 16: lugar no ranking mundial, com 2,2 milhōes de idosos. Em 1985, essa

* Instituto de Medicina Social Universidade do Estado do Rio de Janeiro. população aumentou para 8,9 milhões, colocando o Brasil no 11? lugar. No ano de 1025 , o país deverá 
estar ocupando o sexto lugar no ranking, com uma população acima de sessenta anos estimada em 33,8 milhões. No período compreendido entre o ano de 1950 e 2025 , a população brasileira terá aumentado cinco vezes, enquanto o número de idosos será quinze vezes maior.

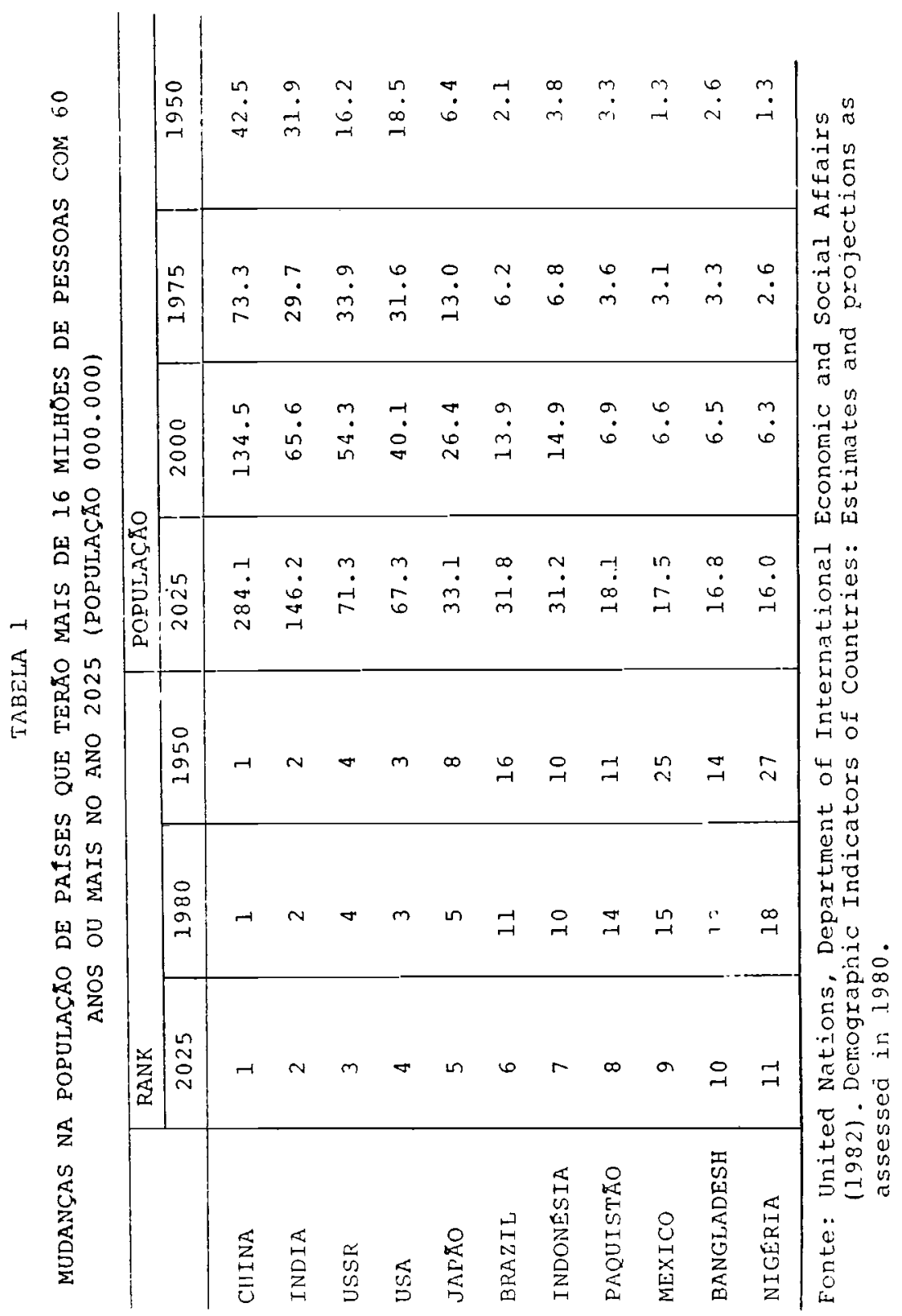


O envelhecimento da populaçāo mundial é um fenômeno novo, ao qual mesmo os países desenvolvidos ainda estão tentando se adaptar. O que era no passado uma marca de alguns poucos países passou a ser uma experiência crescente em todo o mundo.

A tualmente, os pesquisadores reconhecem que os avanços médicos contribuíram para o aumento da expectativa de vida da população; todavia, a razão principal para essa ampliação está associada a elevação da qualidade do nível de vida. Apesar de muito longe do ideal, se compararmos hoje com trinta ou quarenta anos atrás percebe-se uma melhoria nutricional, elevação dos níveis de higiene pesssoal, melhores condições sanitárias em geral e, particularmente, condições ambientais no trabalho e nas residências muito mais adequadas que anteriormente.

No Brasil, esse conjunto de fatores levou a uma acentuada reduçāo nas taxas de mortalidade, particularmente nos primeiros anos de vida. Entretanto, mais do que a diminuição da mortalidade, a explicação para o crescimento da população com mais de sessenta anos está na drástica redução nas taxas de fecundidade, principalmente nos centros urbanos. No Brasil, as razões para a mudança do padrāo reprodutivo são várias. De um lado, fruto do intenso processo de urbanização da população brasileira (Tabela 2), há uma necessidade crescente de limitação da família ditada pelo modus vivendi dos grandes centros urbanos (principalmente em um contexto de crise econômica), caracterizado, entre outras coisas, por uma progressiva incorporação da mulher à força de trabalho, e também pelas mudanças de padrōes sócio-culturais decorrentes da propria migração e da ação massificadora dos meios de comunicação (sobretudo a televisão), que, por sua vez, veiculam um padrão de vida caracterizado, principalmente, por famílias pequenas. Associada a esse contexto, pode-se observar uma crescente difusão de meios contraceptivos no Brasil.

TABEIA 2

POPULAÇÃO RURAL E IRBANA NO BRASIL, 1940 - 2025

\begin{tabular}{|c|c|c|c|c|c|c|c|c|c|c|}
\hline \multicolumn{4}{|c|}{ População } & \multicolumn{7}{|c|}{ Percentagem $(\%)$} \\
\hline & 170 & 19 & 19 & 1770 & $14:$ & 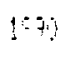 & $\because n$ & 219 & $\because$ & $\because=$ \\
\hline$\dot{Z}-\dot{3}$ & $\because . \vdots$ & $\therefore \therefore$ & $=\therefore 7$ & $\therefore \therefore i$ & - & $\therefore \therefore$ & $\because \because$ & $17 . \pm$ & $\because \therefore=$ & $\because \therefore:$ \\
\hline $\ln 103$ & $3 \cdot \bar{c}$ & 3 & 451 & 5.5 .5 & bi.t & 7.57 & 79.3 & $\because x$ & 6.1 & 58 \\
\hline Total & 10 & 100 & 10 & 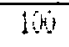 & 16 & 130 & 100 & $\ln$ & 16 & $1 \mathrm{int}$ \\
\hline
\end{tabular}

Fonte: Anuärio Estatístico do Brasil, IBGE, 1981 (1940-1980) Projeção da População, IBGE-CELADE, 1987 (1990-2025) 


\section{Cungl nud Urtan Fopulation in Eraril}

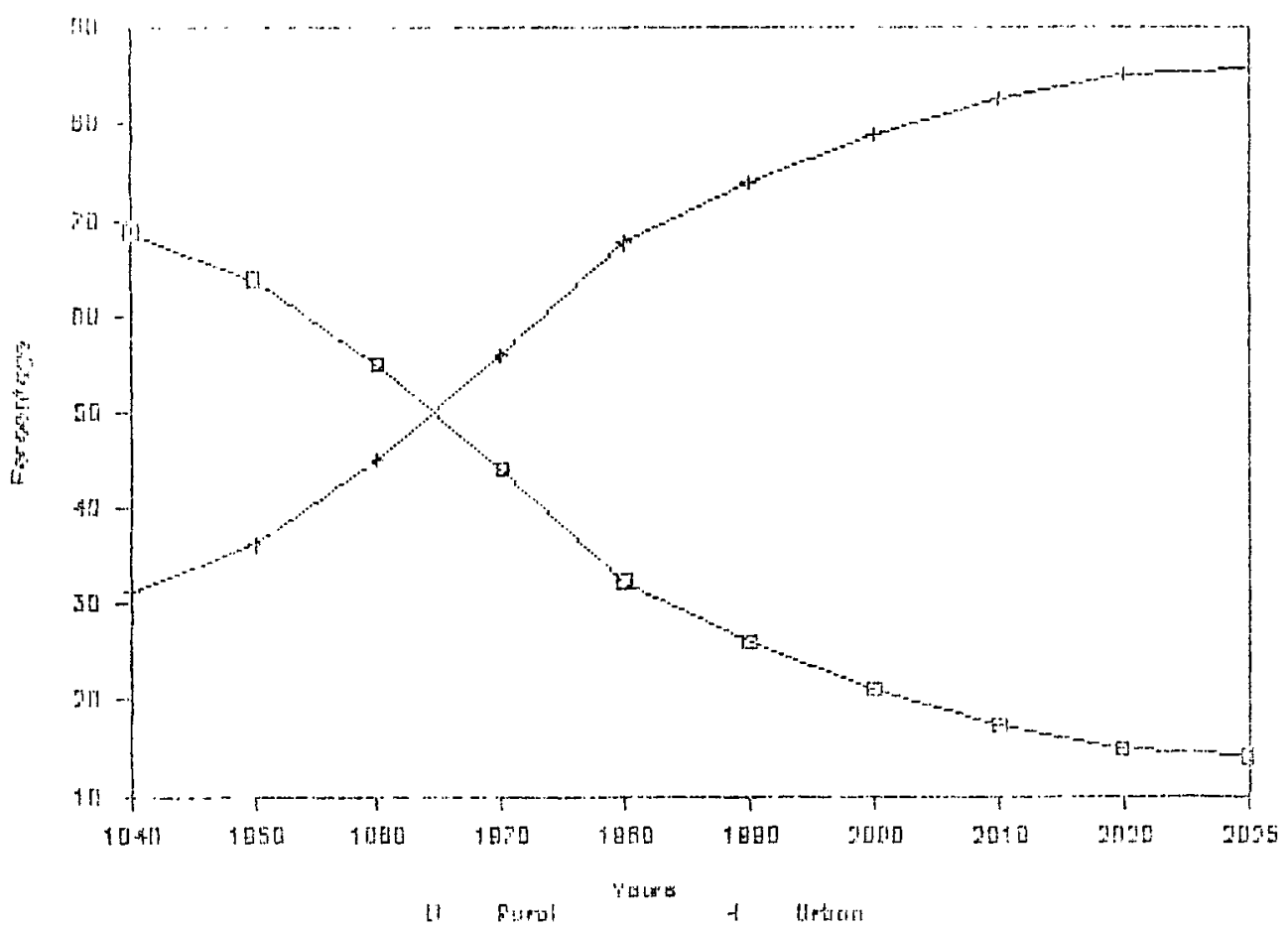

A conjugação desses fatores se expressa, a médio prazo, numa significativa mudança do padrão demográfico do país (de altas taxas de mortalidade e natalidade para taxas relativanente baixas de mortalidade e natalidade). Este processo é conhecido por "transição demográfica", e se expressa por três momentos bem demarcados. O primeiro estágio é caracterizado pela mortalidade concentrals nos primeiros anos de vida e uma grande proporção de população jovem; quando o país entra no segundo estágio, a mortalidade cai, as taxas de crescimento etário aumentam, e a proporção dos grupos jovens decresce. Com o declínio da fecundidade, no terceiro estágio, a proporção dos grupos etários jovens decresce, e a proporção da população em idade produtiva e idosa se amplia. Se ocorre um declínio geral na mortalidade (inclusive o declínio nos grupos idosos), ocorrerá, mais adiante, um aumento da proporção de idosos. O processo é portanto dinâmico e para que uma população envelheça é necessário: 
1. Sobre essa discussāo relativa ao envelhecimento populacional, ver: Kalache A. et al (1987) e Ramos LR. et al. (1987). que nasçam muitas crianças; que as mesmas sobrevivam até idades avançadas e que, simultaneamente, o número de nascimentos diminua. Com isso, a entrada de jovens na população decresce, e a proporção daqueles que sobrevivem até idades mais avançadas passa a crescer, aumentando, deste modo, a proporçāo de idosos na população.

No Brasil, a taxa de natalidade nos anos 60 era consideravelmente maior do que a atual. A base da pirâmide populacional de hoje é menor do que a de algumas décadas passadas, o que significa que a proporção de nascimentos está decrescendo; conseqüentemente, as demais faixas etárias aumentam. A geraçāo nascida na década de 60 será, no ano 2020 , a responsável pela pressāo no topo da pirâmide populacional, fazendo-a ficar com um contorno mais retangular, caso seja mantida a tendência de baixo índice de natalidade. Na Alemanha Ocidental, por exemplo, as taxas atuais de crescimento natural são negativas ou seja, o número de nascimentos é menor do que o de mortes. Isso faz com que hoje sua pirâmide populacional mostre uma base bem menor em relaçāo a décadas passadas, e, portanto, um aumento da proporçāo das demais faixas etárias nos outros segmentos da pirâmide.

A expressão definitiva desse envelhecimento pode ser observado na pirâmide populacional que se transforma, passando de um modelo de populaçáo em crescimento (forma piramidal) para um modelo de população estabilizada (forma "em barril" ou retangularizada). Na Figura 1, observam-se as pirâmides populacionais para o Brasil no ano de 1940 (antes do acentuado declínio na mortalidade e fertilidade), em 1970 (já iniciado o processo de transição demográfica), e no ano 2000 (em que se projetam os efeitos decorrentes das alterações nas taxas de mortalidade e fertilidade neste final de século). Ficam nítidos a tendência a um estreitamento da base da pirâmide, devido à mènor entrada de recém-nascidos na população, e um alargamento das porções média e superior, significando maior proporção de pessoas atingindo idades avançadas...(1)

\section{MUDANÇAS NOS PADRÕES DE MORTALIDADE E MORBIDADE}

A situação no Brasil, analisada por Imhof (1985) e ilustada através de seis capitais brasleiras na Tabela 3 , demonstra claramente essas transições nos padrōes da mortalidade da população destas capitais brasileiras. Em 1930, quase a metade das mortes ocorridas foi causada por doenças infecciosas e parasitárias. Em 1980 , tais doenças foram responsáveis por pouco mais

Cademos de Saúde Pública, RJ, 4 (4): 382-397, out/dez, 1988 
de $10 \%$ das mortes, praticamente a mesma percentagem de mortes causadas por doenças respiratórias ou por câncer. O grupo integrado por doenças cardiovasculares passou a primeiro lugar, tendo sido responsável, em 1980, por um terço das mortes no Brasil. Observa-se, contudo, que as diferenças regionais são grandes - por exemplo, no Rio de Janeiro, metade das mortes é causada por doenças cardiovasculares, enquanto em Fortaleza a proporção diminui para menos de um quarto.
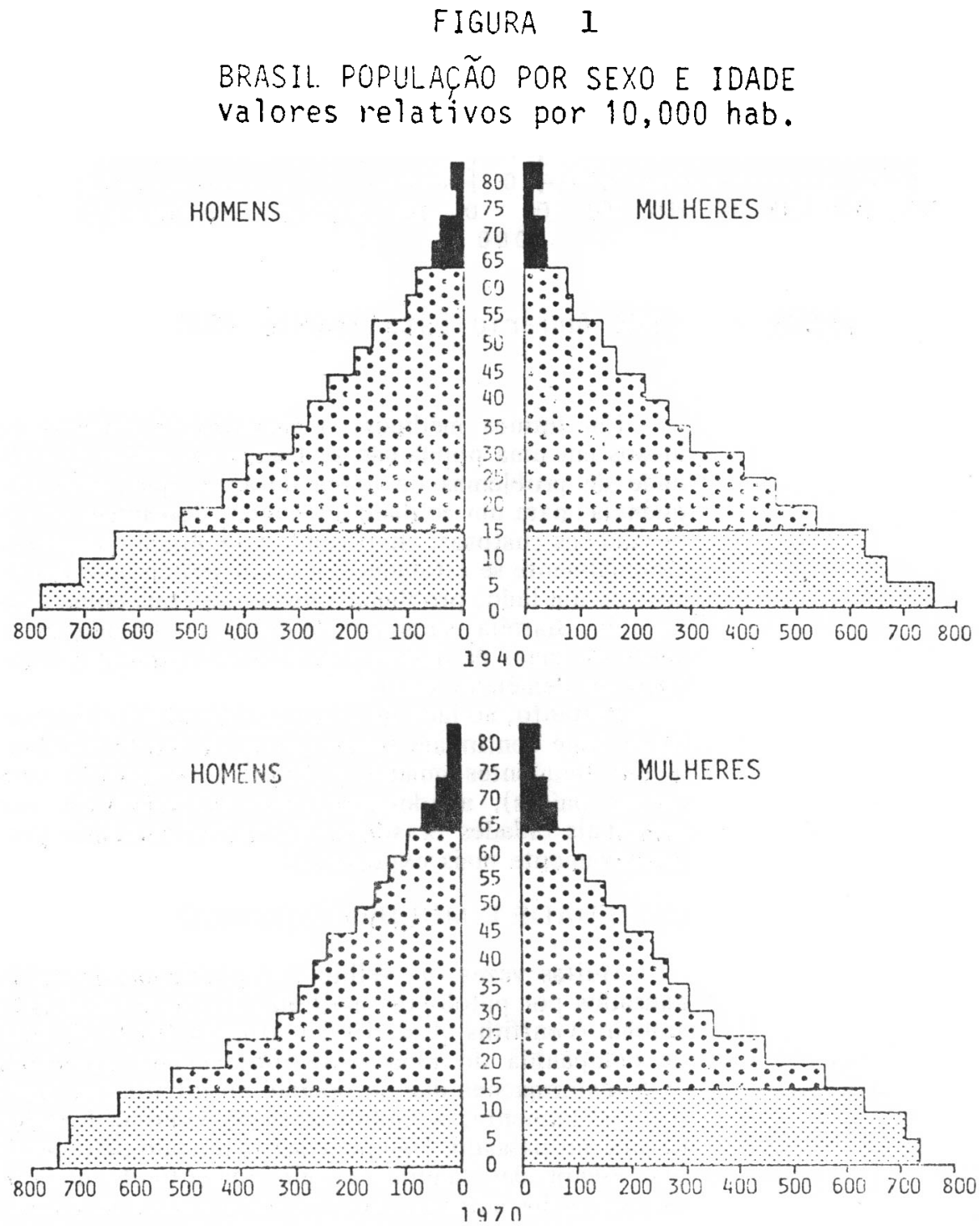


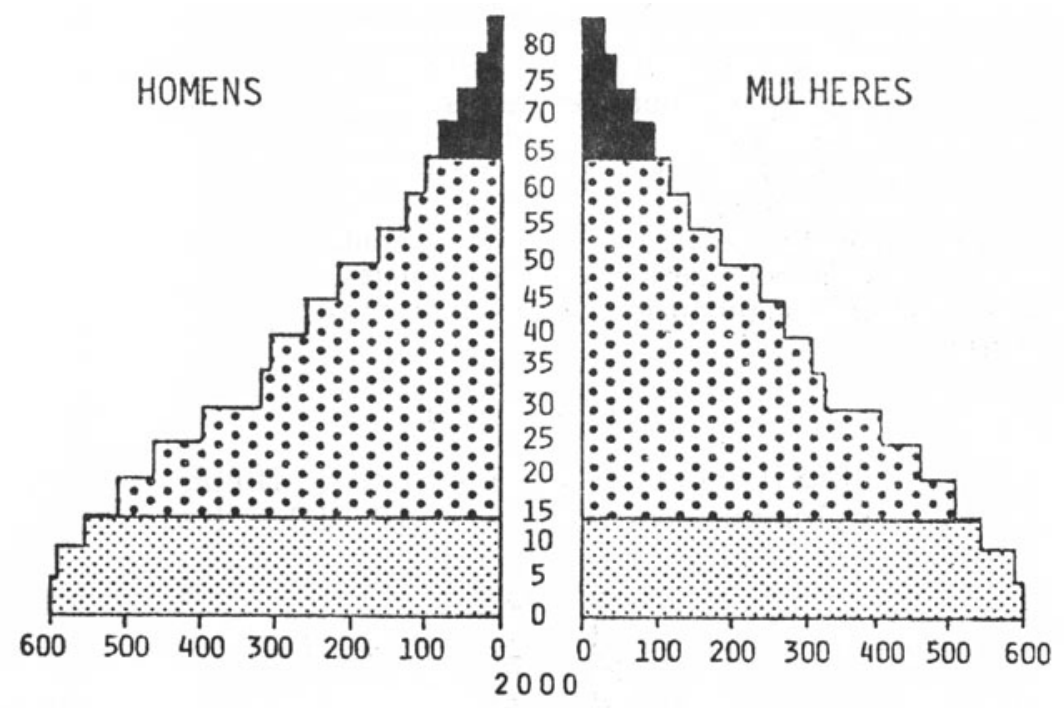

FONTE : IBGE Anuario Estatistico 1981

Em termos médicos, o aumento do número de idosos em uma população se traduz em maior quantidade de problemas de longa duração, que, com freqüência, para um cuidado adequado, dependem de intervençōes custosas, envolvendo tecnologia complexa. Gradualmente se estabelece uma competição por recursos: de um lado, problemas prementes, tais como desnutrção, diarréia, sarampo; de outro, um número crescente de casos de diabetes, acidentes vasculares cerebrais ou demência senil.

Portanto, ao lado de doenças infecciosas e parasitárias (que continuam sendo causas de morte relativamente freqüentes quando o Brasil é comparado com outros países), as doenças crônicas, sobretudo nas principais cidades brasileiras, estão se tomando progressivamente mais expressivas.

\section{SOCIEDADE E MULHERES IDOSAS}

Muitas vezes, na velhice, os problemas de saúde causados por patologias múltiplas são agravados pela solidão (Graffiths et al. 1987 e Murphy 1983). A falta de companhia do idoso está intimamente associada às transformações que se operam no interor das famílias. Atualmente, a mobilidade das famílias é maior do que no passado. Isso pode ser explicado pelo tamanho menor das famílias e pelo aumento do número de separações entre os casais. Essa mudança de padrão 
de família extensa para família nuclear traz como consequêencia para o idoso a diminuição do suporte familiar levando-o muitas vezes a ter que morar só ou com parentes distantes. Essa situação já é há algum tempo observada nos países desenvolvidos, e tudo faz crer que será entre nós um problema crescente (Timaeus 1986).

Um expressivo exemplo da mudança de atitude da sociedade perante o idoso pode ser observado no comentário enunciado por Chow (1983) em relação ao tradicional ditado chinês: "Ter um velho em casa é como ter um tesouro no lar". Segundo ele, este provérbio, mesmo nas sociedades orientais, não é mais levado a sério, devido às transformaçōes sociais, culturais e econômicas do mundo atual, o que faz com que o idoso se sinta rejeitado e indesejado, inclusive no próprio seio familiar.

TABELA 3

CAUSAS DE MORTE EM 6 CAPITAIS BRASILEIRAS PERCENTAGEM DO TOTAL DE MORTES

\begin{tabular}{|c|c|c|c|c|c|c|c|}
\hline CNUSAS MORTE & ANO & RJ & $S P$ & PA & BH & FO & LE \\
\hline INEECCIOSAS & $\begin{array}{l}30 \\
40 \\
50 \\
60 \\
70 \\
80\end{array}$ & $\begin{array}{c}44 \\
42 \\
33 \\
22 \\
9 \\
5\end{array}$ & $\begin{array}{c}39 \\
35 \\
25 \\
14 \\
12 \\
8\end{array}$ & $\begin{array}{c}44 \\
42 \\
36 \\
25 \\
11 \\
5\end{array}$ & $\begin{array}{l}45 \\
42 \\
35 \\
26 \\
20 \\
12\end{array}$ & $\begin{array}{l}55 \\
65 \\
50 \\
35 \\
12 \\
20\end{array}$ & $\begin{array}{l}59 \\
60 \\
49 \\
35 \\
24 \\
21\end{array}$ \\
\hline CIRCULATÓRIAS & $\begin{array}{l}30 \\
40 \\
50 \\
60 \\
70 \\
80\end{array}$ & $\begin{array}{l}11 \\
17 \\
21 \\
31 \\
34 \\
41\end{array}$ & $\begin{array}{l}12 \\
17 \\
12 \\
28 \\
30 \\
34\end{array}$ & $\begin{array}{l}11 \\
15 \\
21 \\
20 \\
34 \\
38\end{array}$ & $\begin{array}{l}13 \\
15 \\
20 \\
23 \\
23 \\
27\end{array}$ & $\begin{array}{c}9 \\
12 \\
8 \\
8 \\
6 \\
20\end{array}$ & $\begin{array}{c}11 \\
9 \\
12 \\
11 \\
21 \\
25\end{array}$ \\
\hline NEOPLÁSICAS & $\begin{array}{l}30 \\
40 \\
50 \\
60 \\
70 \\
80\end{array}$ & $\begin{array}{l}3 \\
4 \\
7 \\
10 \\
13 \\
14\end{array}$ & $\begin{array}{c}4 \\
7 \\
10 \\
13 \\
11 \\
12\end{array}$ & $\begin{array}{c}4 \\
6 \\
9 \\
12 \\
15 \\
17\end{array}$ & $\begin{array}{c}4 \\
4 \\
6 \\
9 \\
10 \\
10\end{array}$ & $\begin{array}{l}1 \\
2 \\
1 \\
2 \\
4 \\
7\end{array}$ & $\begin{array}{r}2 \\
2 \\
3 \\
5 \\
\because \quad 9 \\
\because \quad 9\end{array}$ \\
\hline RESPIRATÓRIAS & $\begin{array}{l}30 \\
40 \\
50 \\
60 \\
70 \\
80\end{array}$ & $\begin{array}{c}13 \\
14 \\
11 \\
7 \\
9 \\
9\end{array}$ & $\begin{array}{c}15 \\
14 \\
9 \\
9 \\
11 \\
12\end{array}$ & $\begin{array}{c}11 \\
14 \\
8 \\
7 \\
9 \\
12\end{array}$ & $\begin{array}{c}14 \\
11 \\
6 \\
9 \\
9 \\
12\end{array}$ & $\begin{array}{c}10 \\
7 \\
4 \\
2 \\
4 \\
6\end{array}$ & $\begin{array}{c}9 \\
10 \\
10 \\
10 \\
10 \\
9\end{array}$ \\
\hline EXTERNAS & $\begin{array}{l}30 \\
40 \\
50 \\
60 \\
70 \\
80\end{array}$ & $\begin{array}{c}3 \\
3 \\
4 \\
8 \\
10 \\
8\end{array}$ & $\begin{array}{l}4 \\
3 \\
4 \\
4 \\
7 \\
7\end{array}$ & $\begin{array}{l}2 \\
2 \\
3 \\
6 \\
6 \\
8\end{array}$ & $\begin{array}{l}4 \\
2 \\
3 \\
6 \\
6 \\
7\end{array}$ & $\begin{array}{l}1 \\
2 \\
2 \\
2 \\
5 \\
6\end{array}$ & $\begin{array}{l}2 \\
1 \\
2 \\
2 \\
8 \\
8\end{array}$ \\
\hline
\end{tabular}

LEGENDA: $R J=$ Rio de Janeiro, $S P=$ Sao Paulo, $P A=$ Porto Alegre,

$B H=$ Belo Horizonte $F O=$ Fortaleza, $B E=$ Belem

FONTE: Ramos, IR, et ali., Envelhecimento popujacional: uma real idade brasilej.ra. Rev. Saúde Püblica, S.Paulo, 21:211-24,1987

Cademos de Saúde Pública, RJ, 4 (4): 382-397, out/dez, 1988 
A diminuição do status social do idoso é patente. $\mathrm{O}$ que antigamente era tido como sua maior riqueza e o colocava numa posição de destaque na sociedade - seu saber e conhecimento acumulado, frutos da longa experiência de vida - nos dias atuais não é mais valorizado. A ideologia do saber atual é gerada pelo conhecimento tecno-científico, dominado pelos jovens, e que exclui quase que por completo o idoso (Cowgill 1968). São poucos (talvez apenas alguns artistas, políticos e profissionais liberais) os que conseguem ser considerados melhores em idade relativamente avançada do que quando jovens.

Além disso, o intenso processo de urbanização que se processa no Brasil só faz reforçar as dificuldades dos idosos. Aqueles que, com toda a família, vieram buscar melhor sorte nos centros urbanos certamente enfrentaram todas as dificuldades de trabalho - que requer muitas vezes a aquisição de novas habilidades -, como também de adaptação aos diferentes valores sociais.

Se para o idoso em geral essas dificuldades são parte do seu dia-a-dia, a mulher idosa tem seus problemas específicos, o que torna esse grupo alvo de especial atenção.

O crescente aumento da expectativa de vida ao nascer da população mundial, apesar de extensivo a ambos os sexos, não ocorre de modo uniforme. No Brasil, entre 1920 e 1982 , a população experimentou um aumento de quase trinta anos de vida (Tabela 4).

TABELA 4

EXPECTATIVA DE VIDA AO NASCER BRASIL 1900 A 2020 AMBOOS OS SEXOS

ANOS

1900

1910

1920

1930

1940

1950

1960

1970

1980

2000

2020
EXP. VIDA AO NASCER

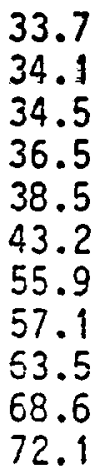

33.7

34.1

34.5

36.5

38.5

43.2

55.9

57.1

53.5

68.6

72.1

FONTE: 1900-1950 - Santos, JLF - Denngrafia:Estimativas e Projeçoes. Sao Paulo, FAUUSP, 1978

1960-2020 - United Nations - Periodical on Ageing 84 vol 1 no 11985 
No entanto, o aumento da expectativa de vida ao nascer para a mulher foi mais significativo do que para o homem. Ao lado de diferenças biológicas como por exemplo o fator de proteção conferido por hormônios femininos em relação à isquemia coronariana -, há várias explicações para tais diferenças:

1) Difereça de exposiçāo às causas de risco de trabalho (a portante menor repercussāo dos fatores de risco em relaçāo ao homem) - É importante salientar que - Brasil é um recordista em acidentes de trabalho. Como os trabalhos "pesados" são realizados por homens, os acidentes de trabalho ocorrem em maior ní. mero neste grupo.

2) Sāo observadas, entre os indivíduos do sexo masculino, taxas maiores por causas de morte denominadas "externas" (acidentes em geral, acidentes de trânsito, homicídios, quedas, suicídios etc.). No Brasil, as causas de morte compreendidas neste grupo sāo quatro vezes superiores no homem do que na mulher.(2)

3) Diferenças no consumo de tabaco e álcool - Apesar do aumento do consumo do fumo e da bebida alcoólica pela mulher nos dias atuais, estes produtos continuam sendo muito mais consumidos pelos homens. $O$ fumo e o álcool estão associados às causas de morte mais importantes na faixa etária acima de 45 anos (neoplasma e doenças do aparelho circulatório), e, como foi visto, estas causas de mortes, desde a década de 60 , são as mais comuns no Brasil, tendo ultrapassado o grupo de óbitos decorrentes por doenças infectoparasitárias (Tabela 5).

4) Difereças de atitude em relação às doenças e incapacidades físicas - As mulheres sāo, em geral, mais atentas ao aparecimento de sintomas, têm um conhecimento melhor das doenças e utilizam mais os serviços de saúde do que o homem (Lewis 1985). A procura de cuidado médico precoce é explicada como uma das causas de um melhor prognóstico das doenças crônicas para o sexo feminino.

5) Assistência médıco-obstétrica - Hoje é mais comum que no passado, quando a mortalidade relacionada à maternidade estava entre as mais importantes causas de mortes das mulheres e na atualidade é relativamente bajxa.

Esses fatores levam a mulher a ter em média alguns anos de vida a mais do que o homem. Uma conseqüência dessa longevidade da mulher em relação ao homem é a maior freqüência dos longos períodos de doenças crônicas.
2. (Estatística de mortalidade, Ministério da Saúde, 1983 - Taxa de mortalidade por 100.000 hahitantes cm 1980, Homens 94,5 ; $\mathrm{Mu}$ thetes 23,8 ). 


\section{ARTIGO}

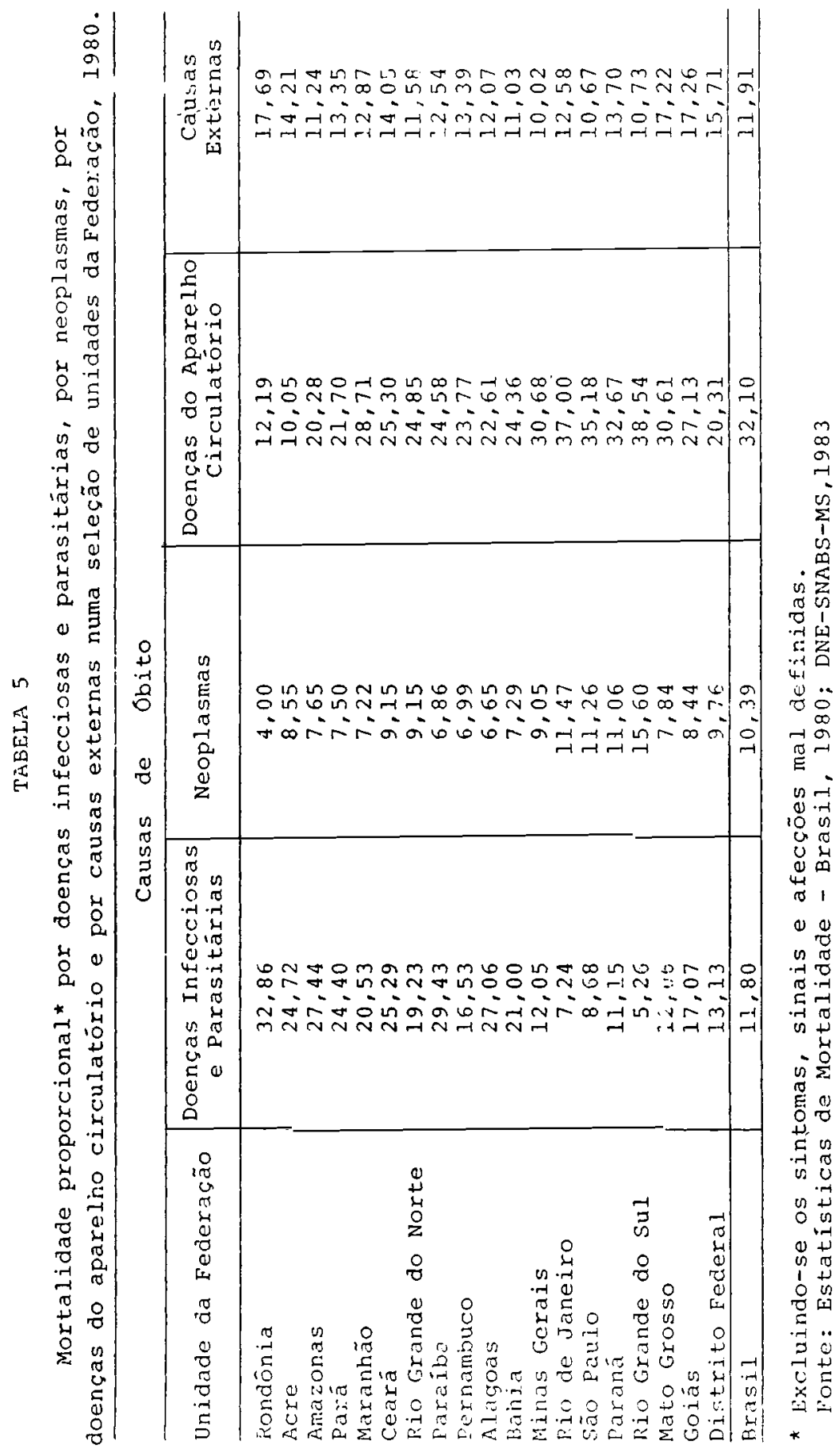


Como foi assinalado, uma das características do idoso é a solidão da velhice; na mulher, este período é ainda maior. Por exemplo, atualmente na Inglaterra dois terços dos dez milhōes de velhos são do sexo feminino, e no grupo etário acima de 85 anos existem para cada homem cinco mulheres vivas (Veras 1985).

Devido a esse maior período de vida, o número de viúvas é maior do que de viúvos. Além de a mulher ter uma vida mais longa, normalmente, por fatores culturais, em todo o mundo, ela se casa mais jovem do que o homem. O resultado da conjunção desses dois fatores é um período mais extenso de solidão entre as mulheres viúvas (ou separadas) em relação ao homem (Tabela 6). Além disso, as taxas de segundo casamento em todas as idades são maiores entre os homens do que entre as mulheres. Casamentos contraídos por pessoas acima de sessenta anos (ainda que o número total seja relativamente pequeno em todo 0 mundo) são significativamente mais comuns entre os homens do que entre as mulheres, variando de 1,5 vezes no Canadá a 4,6 vezes no Japão, conforme os países selecionados na Tabela 7 .

TAHELA 6

PERCENTAGEM DE PRSSOAS CASADAS E VIOUAS, DE 60 ANOS OD MAIS, NURA SELEGÃO DE PAISES, PERIODO 1970

\begin{tabular}{l|c|c|c|c}
\hline \multirow{2}{*}{ PAfses } & \multicolumn{3}{|c}{60 anos ou mais (z) } \\
\cline { 2 - 5 } & \multicolumn{2}{|c|}{ Casados } & \multicolumn{2}{c}{ Viúvos } \\
\cline { 2 - 5 } Africa & lomens & Mulheres & Homens & Mulheres \\
Kenya & & & & \\
Marrocos & 84,3 & 40,9 & 7,5 & 51,0 \\
Asia & 88,6 & 28,2 & 8,3 & 68,2 \\
Japão & & & & \\
Coré1a & 81,1 & 40,0 & 16,6 & 56,6 \\
Amërica liatina & 80,3 & 29,4 & 19,2 & 70,2 \\
Brasil & & & & \\
Chile & 75,1 & 34,0 & 14,4 & 50,2 \\
Cuba & 74,5 & 40,0 & 16,2 & 45,5 \\
América do Norte & 68,2 & 46,9 & 10,6 & 36,9 \\
Estados Un1dos & & & & \\
Europa & & & & \\
França & 76,3 & 44,0 & 13,2 & 44,5 \\
Alemanha Ocidenta1 & & & & \\
Holanda & 75,2 & 41,4 & 14,5 & 45,5 \\
Suécia & 79,4 & 38,4 & 14,3 & 47,6 \\
Reino Un1do & 76,8 & 49,4 & 15,0 & 36,8 \\
\hline
\end{tabular}

Fonte: Myers o Nathanson (1982) 
TABELA 7

CASAMENTOS CONTRATDOS PELA POPUTACCÃO IDOSA DE 60 ANOS OU MAIS, SEGUNDO PRÉVIO ESTADO CIVIL, NUMA SELFCX̃̃o DE PAISES, PERIONO ENTRE 1970 E 1975

\begin{tabular}{|c|c|c|c|c|c|}
\hline \multirow{2}{*}{ PAISES } & \multicolumn{3}{|c|}{ ESTADO CIYIL } & \multirow[b]{2}{*}{ TOTAL } & \multirow[b]{2}{*}{ Nㅡㅇㅡ } \\
\hline & SOLTEIRO & PIŨvo & DIVORCIADO & & \\
\hline \multicolumn{6}{|c|}{ Canadā (1974) } \\
\hline $\begin{array}{l}\text { Homern } \\
\text { Mulher } \\
\text { Razäo H/M }\end{array}$ & $\begin{array}{r}10,7 \% \\
9,9 \% \\
1,63\end{array}$ & $\begin{array}{r}71,1 \% \\
80,1 \% \\
1,34\end{array}$ & $\begin{array}{r}18,2 \% \\
9,9 \% \\
2,78\end{array}$ & $\begin{array}{r}100,0 \% \\
99,9 \%\end{array}$ & $\begin{array}{l}4735 \\
3127 \\
1,51\end{array}$ \\
\hline \multicolumn{6}{|l|}{ Chile (1972) } \\
\hline $\begin{array}{l}\text { Homen } \\
\text { Mulher } \\
\text { Razão H/M }\end{array}$ & $\begin{array}{r}41,6 \% \\
60,9 \% \\
1,74\end{array}$ & $\begin{array}{r}54,5 \% \\
37,0 \% \\
3,76\end{array}$ & $\begin{array}{l}3,9 \% \\
2,1 \% \\
4,67\end{array}$ & $\begin{array}{l}100,0 \% \\
100,0 \%\end{array}$ & $\begin{array}{r}1427 \\
560 \\
2,55\end{array}$ \\
\hline \multicolumn{6}{|l|}{ Franca (1972) } \\
\hline $\begin{array}{l}\text { Homem } \\
\text { Mulher } \\
\text { Razão H/N }\end{array}$ & $\begin{array}{r}14,1 \% \\
18,4 \% \\
1,37\end{array}$ & $\begin{array}{r}61,9 \% \\
54,2 \% \\
2,04\end{array}$ & $\begin{array}{r}24,0 \% \\
27,4 \% \\
1.56\end{array}$ & $\begin{array}{l}100,0 \% \\
100,0 \%\end{array}$ & $\begin{array}{l}6202 \\
3469 \\
1,79\end{array}$ \\
\hline \multicolumn{6}{|c|}{ Grëcia (1975) } \\
\hline $\begin{array}{l}\text { Homem } \\
\text { Mulber } \\
\text { Razão } H / M\end{array}$ & $\begin{array}{r}16,9 \% \\
35,9 \% \\
2,06\end{array}$ & $\begin{array}{r}67,6 \% \\
45,9 \% \\
6,45\end{array}$ & $\begin{array}{r}1.5,5 \% \\
18,2 \% \\
3,74\end{array}$ & $\begin{array}{l}100,0 \% \\
100,0 \%\end{array}$ & $\begin{array}{r}1012 \\
231 \\
4,38\end{array}$ \\
\hline \multicolumn{6}{|c|}{ Itália (1973) } \\
\hline $\begin{array}{l}\text { Homen } \\
\text { Mulher } \\
\text { Razão H/M }\end{array}$ & $\begin{array}{r}16,8 \% \\
49,0 \% \\
0,97\end{array}$ & $\begin{array}{r}48,8 \% \\
34,2 \% \\
4,05\end{array}$ & $\begin{array}{r}34,4 \% \\
16,7 \% \\
5,85\end{array}$ & $\begin{array}{r}1.00,0 \% \\
99,9 \%\end{array}$ & $\begin{array}{l}7359 \\
2587 \\
2,84\end{array}$ \\
\hline \multicolumn{6}{|l|}{ Japào (1975) } \\
\hline $\begin{array}{l}\text { Homem } \\
\text { Mulher } \\
\text { Razão H/M }\end{array}$ & $\begin{array}{r}4,2 \% \\
23,9 \% \\
0,81\end{array}$ & $\begin{array}{r}61,1 \% \\
31,3 \% \\
8,99\end{array}$ & $\begin{array}{r}34,7 \% \\
44,8 \% \\
3,85\end{array}$ & $\begin{array}{l}100,0 \% \\
100,0 \%\end{array}$ & $\begin{array}{r}2666 \\
573 \\
4.61\end{array}$ \\
\hline \multicolumn{6}{|l|}{ Suécia (1975) } \\
\hline $\begin{array}{l}\text { Homem } \\
\text { Mulher } \\
\text { Razão H/M }\end{array}$ & $\begin{array}{l}11,5 \\
24,4 \% \\
0,97\end{array}$ & $\begin{array}{r}46,7 \% \\
42,0 \% \\
2,28\end{array}$ & $\begin{array}{r}41,7 \% \\
33,6 \% \\
2,54\end{array}$ & $\begin{array}{r}99,9 \% \\
100,0 \%\end{array}$ & $\begin{array}{r}537 \\
262 \\
2,03\end{array}$ \\
\hline \multicolumn{6}{|c|}{ Reino Unido (1974) } \\
\hline $\begin{array}{l}\text { Homem } \\
\text { Mulher } \\
\text { Razäo H/M }\end{array}$ & $\begin{array}{r}6,9 \% \\
12,9 \% \\
0,83 \\
\end{array}$ & $\begin{array}{r}68,2 \% \\
72,2 \% \\
1,46 \\
\end{array}$ & $\begin{array}{r}24,9 \% \\
14,8 \% \\
2,60 \\
\end{array}$ & $\begin{array}{r}100,0 \% \\
99,9 \%\end{array}$ & $\begin{array}{r}13540 \\
8128 \\
3.8 \\
\end{array}$ \\
\hline
\end{tabular}

Fonte: Nyers e Nathanson (1082) 
Esse conjunto de fatores nos permite afirmar que a solidão é algo bem mais freqüente e, portanto, mais sentido pela mulher do que pelo homem idoso.

No entanto, não param aí as dificuldades da muIher idosa. Uma outra característica da velhice é a pobreza, e novamente este fato se expressa mais fortemente na mulher.

Como conseqüência da vida atual mais solitária, o idoso, na maioria das vezes, tem que arcar com os custos de manutenção de sua casa. Aquele que não pôde acumular uma poupança durante a vida produtiva tem, em geral, um final de vida em situação financeira pior do que quando trabalhava, já que o valor da aposentadoria, para os que a têm, é inferior aos vencimentos do período produtivo. Além disso, a possibilidade de gerar novos recursos com outro trabalho remunerado a fim de complementar a renda é quase nenhuma. Ainda que não existam proibições legais ao trabalho do idoso, o fato é que praticamente inexistem oportunidades de trabalho. Como a mulher vive mais anos e quase nunca se casa após os sessenta anos; e o apoio de outros membros da familia, tende a decrescer, devido a redução do seu tamanho, adquire contomos mais expressivos.(3)

A associação entre velhice e pobreza já foi extensivamente examinada em outros países (Townsend 1970 e 1975, Hewitt 1974). Em um estudo conduzido na Inglaterra, observou-se que $90 \%$ dos velhos viviam em pensões (Abrams 1980) e que, enquan to $20 \%$ dos velhos ingleses vivem em condição de pobreza, apenas $7 \%$ do resto da populaçāo se enquadram nessa categoria (Townsend 1979).

\section{CONCLUSÃO}

O Brasil, onde por um longo periodo enfrentaremos ainda uma importante demanda de recursos para as áreas de educaçăo e médico-sociais a fim de fazer frente às necessidades da parcela jovem da populaçāo, terá de conviver com um novo grupo populacional a demandar recursos: os idosos. Assim é importante que as açōes do Ministério da Saúde e da Previdência Social estejam cada vez mais preparadas para o crescimento desse grupo etário, já que a questão médicosocial do idoso, particularmente a mulher, face a sua dimensão, exige uma política ampla e expressiva que suprima, ou pelo menos amenize, a cruel realidade que espera aqueles que conseguem viver até idades mais avançadas. Após tantos esforços realizados para prolongar a vida hurıana, seria lamentável não se oferecer as condições adequadas para vivê-la.

Cadernos de Saúde Pública, RJ, 4 (4): 382-397, out/dez, 1988
3. A respeito destas questōes, ver: Beauvoir S. (1972), Lins de Barros M. (1987) e Haddad E. (1986), Veras R, et al. (1987). 
Ageing has now became an universal phenomenon, of increasing importance to developed and developing countries alike. This article discusses the factors which are responsible for the ageing process, and the various stages of the "demographic transition" are discussed also. The consequences for any society with a population that is gradually becoming older are considerable, and they are a particular importance for the health sector. The relatively longer life span of women and the changing role of women and their participation in society are also focused in this paper.

\section{REFERÊNCIAS BIBLIOGRÁFICAS}

1. ABRAMS, M. Beyond three score and ten: a second report on a survey of elderly. London, Age concern, 1980.

2. BEAUVOIR, S. Old age. New York, Penguin Books, 1972.

3. CHOW, N. W. The Chinese family and support of the elderly in Hong-Kong. Gerontologist, 23:584-8, 1983

4. CONWGILL, D. O. The social life of the ageing in Thailand. Gerontologist, 8:159-63, 1968.

5. GRIFFITHS, R. A.; GOOD, W. R.; WATSON, N.P .; O'DONNELL, F. O.; FELL, P. J.; SHAKESPEARE, S. M. Depression Dementia and Disablity in the Elderly. British Journal of Psychiatry, 150, 482-493, 1987.

7 HEWITT, P. Age concem on pensioner incomes. London, Age Concern, 1974.

8. IMHOF, A. E. Mortality problem in Brazil and in Germany: past-present-future: learning from each other? Rev. Saúde públ. São Paulo, 19: 233-50, 1985.

9. KALACHE, A.; VERAS, R. P.; RAMOS, L. R. O envelhecimento da população mundial. Um desafio novo. Rev. Saúde públ., São Paulo, 21: 200-10, 1987.

10. LEWIS, M. Health needs of women as they age. Women \& Hlth, $10(2 / 3): 1-8,1985$.

11. LINS DE BARROS, M. Testemunhos de vida: um estudo antropológico das mulheres na velhice $\mathrm{R}$ io de Janeiro, Zahar, 1987.

12. MINISTÉRIO DA SAÚDE. Secretaria Nacional de Açōes Básicas de Saúde. Estatística de mortalidade - Brasil: 1981. Brasilia, Centro de Documentação do Ministério da Saúde, 1984.

13. MYERS, G. \& NATHANSON, G. Ageing and the family. Wld Hlth Stat., 35: 225-38, 1982.

14. MURPHY, E. The prognosis of depression in old age. Brit. J. Psychiat., 142: 111-9, 1983.

15. RAMOS, L. R.; VERAS, R. P.; KALACHE, A. Envelhecimento populacional: uma realidade brasileira. Rev. Saúde públ., São Paulo, 21: 211-24, 1987.

16. SANTOS, J. L. F. Demografia: estimativa e projeçōes. São Paulo, Faculdade de Arquitetura e Urbaismo da USP, 1978. 
17. TIMACUS I. Families and households of the elderly population: prostepcts for those approaching old age. Ageing and Society, 6: 271-293, 1986.

18. TOWNSEND, P. The family life os old people. New York, Penguin Books, 1970.

19. TOWNSEND, P. Poverty in the United Kingdom. London, Allen Lane, 1975.

20. VERAS, R. P. Living longer in Brazil: demographic changes and challenges for policy makers in health planning. London, 1985 (Thesis - Department of Community Medicine. London School of Hygiene and TRopical Medicine).

21. VERAS, R. P. et al. Crescimento da população idosa no Brasil: transformaçōes e conseqüências na sociedade. Rev. Saúde públ., São Paulo, 21: 225-33, 1987. 